\title{
Synthesis of Aeruginosin Natural Products
}

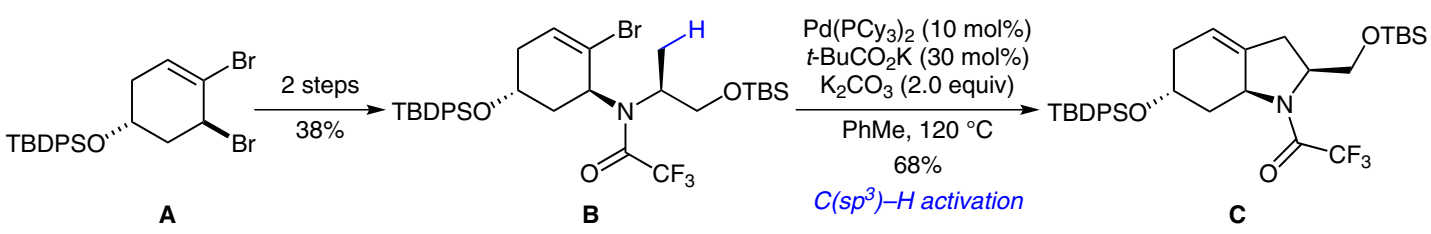

A

B<smiles>[2H]C(NC(=O)C(Cc1ccc(OCc2ccccc2)cc1)OCCCC)C(=O)O</smiles>

5 steps $\downarrow 66 \%$
Gategory

Synthesis of Natural

Products and

Potential Drugs

\section{Key words}

aeruginosin 98B

aeruginosin 298A

marine natural products

serine protease

inhibitor

C(sp $\left.{ }^{3}\right)-H$ bond activation

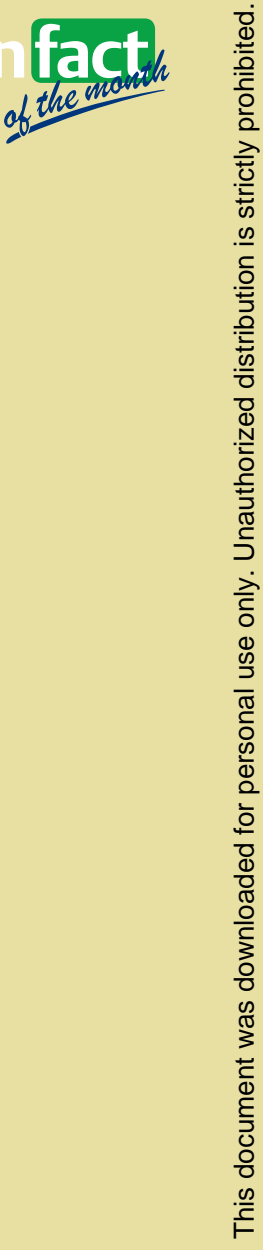

Significance: The marine natural products of the aeruginosin family have been shown to possess high in vitro inhibition of serine proteases. In this communication by Baudoin and co-workers, a novel approach for the synthesis of the core structure using an uncommon $\mathrm{C}\left(\mathrm{sp}^{3}\right)-\mathrm{H}$ bond activation is presented, culminating in the efficient total synthesis of aeruginosins 98B and 298A.
Comment: The synthesis of $\mathbf{B}$, used for the pivotal C-H bond activation step, was accomplished from dibromocyclohexene A in two steps. Previously reported conditions (Angew. Chem. Int. Ed. $\mathbf{2 0 1 2}, 51,10399)$ gave the cyclization product $\mathbf{C}$ in $68 \%$ yield. Its elaboration into key precursor $\mathbf{D}$ allowed for the installation of the peptide as well as the guanidine side chain of both natural products.

sYNFACTS Contributors: Erick M. Carreira, Alberto G. Kravina

Synfacts 2015, 11(5), 0457 Published online: 17.04.2015

Dol: 10.1055/s-0034-1380622; Reg-No.: C01815SF 